\title{
En torno a una copia inédita de la primera edición frustrada de la Summa sacramentorum (1541). El epitomizador Tomás de Chaves y la circulación manuscrita de las lecciones de Francisco de Vitoria In IV Sent
}

On an Ignored Copy of the First Frustrated Edition of the Summa sacramentorum (1541). The Epitomiser Tomás de Chaves and the Manuscript Circulation of Francisco de Vitoria's Lessons In IV Sent

\author{
José Luis Egío García \\ Proyecto La Escuela de Salamanca, Frankfurt/Mainz \\ egio@rg.mpg.de
}

DOI: https://doi.org/10.15366/bp2021.26.004 Bajo Palabra. II Época. No26. Pgs: 75-106 
Recibido: 15-07-2020

Aceptado: 10-10-2020

\section{Resumen}

Mientras que las lecciones de Vitoria sobre la Summa Theologiae de Tomás de Aquino y sus relecciones sobre los llamados 'asuntos de Indias' han sido editadas, traducidas y bastante trabajadas por la historiografía precedente, hasta el punto de dar lugar, en algunos casos, a una literatura repetitiva y tediosa, las lecciones que en los cursos 1529-31 y 1538-39 dedicó al $I V$ de las Sentencias de Pedro Lombardo permanecen inéditas, siendo difícil incluso encontrar literatura al respecto. Este artículo demuestra que fue, precisamente, esta parte de la producción intelectual de Vitoria la que discípulos como Tomás de Chaves comenzaron a hacer circular en manuscritos ya durante la vida del maestro. Los esfuerzos de Chaves quien, como probamos en el artículo gracias al hallazgo de un manuscrito inédito, ya en 1541 tenía listo un compendio sobre la teología sacramental y pragmática de Vitoria — compendio que sólo pudo ver la luz en 1560, bajo el título Summa sacramentorum ecclesiae-, deben ser vistos como un episodio clave en la consolidación de la fama póstuma de Vitoria y la emergencia de la Escuela de Salamanca.

Palabras clave: Escuela de Salamanca, Francisco de Vitoria, Tomás de Chaves, literatura pragmática, producción de conocimiento normativo.

\section{Abstract}

While Vitoria's lessons on Aquinas' Summa Theologiae and his relectiones on the so-called 'asuntos de Indias' have been edited, translated, and well-studied by the preceding historiography, to the point of giving rise, in some cases, to a repetitive and tedious literature, Vitoria's lessons during the courses 1529-31 and 1538-39, dedicated to the $I V$ Book of the Sentences of Peter Lombard remain unpublished, being difficult even to find literature on the subject. This article shows that it was precisely this part of Vitorias intellectual production that disciples such as Tomás de Chaves began to make circulate in manuscripts during the lifetime of their master. The efforts of Chaves who, as I prove in the article thanks to the discovery of an unpublished manuscript, already in 1541 had a compendium on the sacramental and pragmatic theology of Vitoria ready - a compendium that could only be published in 1560, under the title Summa sacramentorum ecclesiae - must be seen as a key episode in the consolidation of $\mathrm{Vi}$ toria's posthumous fame and the emergence of the School of Salamanca.

Keywords: School of Salamanca, Francisco de Vitoria, Tomás de Chaves, pragmatic literature, normative knowledge production. 


\section{Introducción. La teología sacramental y pastoral, una parte sustancial del pensamiento de Vitoria desatendida por la historiografía.}

Publicados POR PRIMERa VeZ EN I 560-62, quince años después de la muerte de Vitoria, la Summa sacramentorum ${ }^{1}$ y el Confessionario útil y provechoso ${ }^{2}$, manuales para la administración de los sacramentos y la práctica de la confesión, reflejan una parte importante del pensamiento normativo de Francisco de Vitoria (1483-1546). Se trata de una parte de su producción intelectual poco tenida en cuenta por la historiografía sobre Vitoria y la Escuela de Salamanca, que ha tendido a concentrarse en sus relecciones indianas y en una serie de temas clásicos (los títulos de la conquista, el derecho natural y de gentes, los tipos de ley, la actualización escolástica del pensamiento de Tomás de Aquino,...), hasta el punto de producir una literatura reiterativa y cuya lectura genera una sensación de agotamiento y hastío.

Editados por uno de los alumnos de Vitoria, Tomás de Chaves, quien asistió a los cursos dictados por el maestro en sus primeros años de docencia en Salamanca, la Summa sacramentorum y el Confessionario constituyen obras importantes para mostrar de qué manera fueron sintetizados y epitomizados los cursos de Vitoria en Salamanca y cómo esta parte de su pensamiento se divulgó por todo el orbe cristiano con mucha más rapidez e intensidad que las temáticas recogidas en las más conocidas y estudiadas Relectiones theologicae.

Con independencia del valor que concedamos a este tipo de temas y escritos, se trata de los primeros materiales vitorianos que se imprimieron en la Península Ibérica, publicándose poco después de la editio princeps de las Relectiones de Vitoria en Lyon (1557) y algunos años antes de su primera edición en España (1565). La publicación de la Summa sacramentorum (1560) y el Confessionario (1562) debe ser considerada, por tanto, como un paso muy significativo en la divulgación y la fama póstuma de Vitoria. Estos manuales pragmáticos de teología pastoral son, además, los eslabones intelectuales que permitieron la transmisión del pensamiento vitoriano desde el espacio erudito de las aulas de la Universidad de Salamanca hasta iglesias y parroquias, es decir, a la vida cotidiana de sacerdotes y feligreses en todo el mundo católico.

\footnotetext{
${ }^{1}$ VITORIA, F. de, CHAVES, T. de, Summa sacramentorum, Valladolid, Sebastián Martínez, 1560.

2 VITORIA, F. de, CHAVES, T. de, Confessionario util y provechoso, Santiago, [Luis de Paz], 1562.
} 
Pese a ello, tanto las obras como su compilador, el dominico Tomás de Chaves, han sido prácticamente ignorados por la historiografía e incluso atacados por aquellos especialistas en Francisco de Vitoria que consideraron estas síntesis pedagógicas como una vulgarización excesiva y hasta obscena del pensamiento del maestro. Este tipo de ataques no debería sorprendernos si pensamos en el desdén con que los historiadores de la filosofía, la teología y el derecho han considerado habitualmente la literatura pragmática. Se trata, en todo caso, de un desprecio enormemente perjudicial y que margina, al prejuzgarlas como obras indignas de atención, tanto a varios de los escritos de Vitoria como a una amplísima parte de la producción impresa e intelectual de la Primera Edad Moderna.

Repitiendo acríticamente tales actitudes o volviendo a andar los caminos ya 'trillados' por la historiografía más convencional, corremos también el riesgo de perder de vista la perspectiva histórica sobre unos materiales a los que sus coetáneos y los estudiosos de los siglos XVII y XVIII concedieron mucho valor. Barbosa Machado, Quétif, Échard y otros muchos autores de compendios y enciclopedias literarias mencionan siempre con gran respeto esta Summa sacramentorum, insistiendo precisamente en el carácter pragmático del libro como su rasgo más positivo y la clave de su gran éxito editorial. En el mismo sentido, a finales del siglo XVI, el dominico Juan de Marieta presentaba el libro como un instrumento "muy necesario para todos los Curas, y los demas que administran Sacramentos" 3 .

Los especialistas en teología y géneros de literatura religiosa siempre tuvieron la obra en alta estima. En la década de los 30, Friedrich Stegmüller indicaba que la Summa sacramentorum fue "el manual de teología pastoral más utilizado por el clero español en el siglo XVI" ${ }^{\prime}$. De hecho, mientras que las Relectiones se editaron en contadas ocasiones a lo largo de los siglos XVI y XVII ${ }^{5}$, tanto la Summa sacramentorum como el Confessionario se imprimieron decenas de veces en diversas partes de España y Europa. Que la afirmación de Stegmüller no fue una especie de exageración hagiográfica es fácil de probar. Según expertos en la historia del libro como Rubén González, la Summa sacramentorum conoció 81 ediciones $^{6}$. En su reciente aproximación

\footnotetext{
${ }_{3}^{3}$ MARIETA, J. de, Historia Eclesiastica de todos los santos, de España. Segunda parte, Cuenca, Pedro del Valle, 1596, f. $211 \mathrm{r}$.

${ }^{4}$ STEGMÜLLER, F., Francisco de Vitoria y la doctrina de la gracia en la Escuela Salmantina, Barcelona, 1934. Citado por ISERLOH, E., GLAZIK, J., JEDIN, H., History of the Church. Vol. V. Reformation and Counter Reformation, Londres, Burns \& Oates, 1980, p. 537.

${ }^{5}$ Grawert menciona las ediciones de Lyon (1557), Salamanca (1565), Ingolstadt (1580), Lyon (1604), Amberes (1604), Venecia (1626), Salamanca (1680) y Colonia (1696). GRAWERT, R., "Francisco de Vitoria: Naturrecht - Herrschaftsordnung - Völkerrecht", Der Staat 39:1 (2000), pp. 110-125, p. 114.

${ }^{6}$ GONZÁLEZ, R., Francisco de Vitoria. Estudio bibliográfico, Buenos Aires, Institución Cultural Española, Buenos Aires, 1946, p. 33.
} 
bibliográfica a los libros publicados en la Península Ibérica, Wilkinson ofrece una lista de treinta y tres ediciones sólo para el siglo XVI ${ }^{7}$. Aunque el listado de Wilkinson, basado en catálogos de biblioteca, contiene algunos datos inexactos y varias ediciones fantasmas (incluyendo tres supuestas ediciones en castellano) ${ }^{8}$, se trata de números muy significativos y que nos permiten, sin lugar a dudas, hablar de la Summa sacramentorum (y también del Confessionario) como best-seller editoriales de su tiempo.

Varias de las ediciones del libro fueron publicadas fuera de los reinos españoles, en importantes centros de impresión como Lisboa, Amberes, Roma, Venecia y Ruán, haciendo esta parte del pensamiento de Vitoria accesible a la práctica totalidad del público lector europeo. Se trata también de un libro que tuvo una amplia difusión en la América colonial y que suele aparecer con frecuencia en los documentos que reflejan la compra y venta de libros en los siglos XVI y XVII ${ }^{9}$. Sólo en el Fondo Reservado de la Biblioteca Nacional de México ${ }^{10}$, se contabilizan no menos de nueve ediciones diferentes y dieciséis ejemplares del libro, incluyendo la editio prínceps.

\section{Algunos datos biográficos sobre Tomás de Chaves, discípulo 'menor' de Vitoria.}

Antes de entrar en un anÁlisis detallado de algunos de los contenidos de la Summa sacramentorum, cabe decir algunas palabras sobre la vida de Tomás de Cha-

\footnotetext{
WILKINSON, A., Iberian Books: Books Published in Spanish or Portuguese or on the Iberian Peninsula before 1601, Brill, Leiden / Boston, 2010, pp. 362-363.

8 Nuestra propia investigación sobre las ediciones de la Summa nos ha llevado a descartar la existencia de una traducción al castellano. En el catálogo publicado por Brill, Wilkinson menciona una primera edición en castellano impresa en Salamanca en 1575 y conservada en la Biblioteca Pública del Estado de Ciudad Real. Tras consultar a Esteban Jiménez González, quien trabaja como soporte técnico en la BPECR, pude verificar que la información es errónea y que el libro que posee la biblioteca es, de hecho, una copia la edición latina publicada en Salamanca (por Portonaris) este mismo año. Lo mismo sucede con la segunda edición en castellano de la obra, que de acuerdo a Wilkinson habría sido impresa en Huesca en 1588 y se encontraría en la Biblioteca General de la Universidad de Zaragoza. Tras consultar a Paz Miranda, directora de la biblioteca, pude verificar que esta información también es errónea. El libro que posee la BGUZ es una copia de la edición latina impresa en Huesca (por Juan Pérez de Valdivieso) en 1588. Finalmente, en enero de 2018 pude comprobar personalmente en la Biblioteca Nacional de México que otra de las presuntas ediciones castellanas mencionadas por Wilkinson, de la que se informaba había sido impresa en Madrid en 1565, es, en realidad, un ejemplar de un manual para sacerdotes sin relación con la obra de Chaves y Vitoria. La persistencia de este tipo de errores en publicaciones recientes muestra que la investigación sobre la Summa sacramentorum está todavía en sus comienzos.

9 Leonard reproduce un "Pagaré de Alfonso Losa, mercader de libros. México, 22 de diciembre de 1576", donde se encuentra una referencia a " 2 Sumas de Sacramento, papelones a 4 reales". LEONARD, I., Books of the Brave, California, University of California Press, 1992, p. 349.

${ }^{10}$ YHMOFF CABRERA, Jesús, Catálogo de los impresos europeos del siglo XVI que custodian la Biblioteca Nacional, Tomo I, México, UNAM, 1996, pp. 637-643. Yhmoff Cabrera registra las siguientes ediciones: Valladolid, 1560; Lisboa, 1564; Salamanca, 1570; Salamanca, 1571; Salamanca, 1527; Salamanca, 1573; Salamanca, 1575; Salamanca, 1579; Salamanca, 1584.
} 
ves, sin duda, uno de los más oscuros y menos conocidos discípulos de Vitoria. Al igual que respecto a los varios Sotos y Medinas que frecuentaron la Facultad de Teología salmantina en el siglo XVI, la literatura escrita hasta la fecha ha tendido a confundir a Tomás de Chaves con otros estudiantes apellidados Chaves u oriundos de Chaves, localidad portuguesa fronteriza con España. Se suele confundir, en particular, a Tomás de Chaves con Diego de Chaves, dominico de renombre mucho mayor, educado también en el convento de San Esteban de Salamanca y que llegó a ser catedrático universitario en Salamanca y Santiago y confesor de Felipe II ${ }^{11}$.

Dependiendo de la fuente, Tomás de Chaves es identificado como portugués ${ }^{12}$ o como extremeño ${ }^{13}$. Si fuera realmente portugués, el caso de Chaves no sería excepcional. Según Beltrán de Heredia, durante el siglo XVI, los portugueses representaban alrededor del quince por ciento del total de los estudiantes inscritos en la Universidad de Salamanca, es decir, unos mil estudiantes en los años de mayor matrícula ${ }^{14}$. Chaves profesó en el Convento de San Esteban en 1524 y asistió a los cursos de Vitoria a finales de la década de 1520 y durante la década de 1530, como el propio dominico explica en las cartas prefatorias a las diferentes ediciones del libro. Según algunos académicos, no sólo estudió teología, sino que también habría estudiado derecho canónico en la Universidad de Salamanca ${ }^{15}$, aunque éste es un dato que debe ser verificado.

Con independencia de la amplitud que llegaran a tener sus estudios y de los aspectos que aún desconocemos sobre su vida académica, Chaves debió de interrum-

${ }^{11}$ CUERVO, J., Historiadores del convento de San Esteban de Salamanca, Salamanca, Imprenta Católica Salmanticense, 1914, Tomo I, p. 297. Algunas publicaciones llegan a confundir a nuestro Tomás de Chaves con un homónimo del siglo XVI, "Padre presentado" como el Chaves discípulo de Vitoria, que ejerció de misionero en la Provincia de San Juan Bautista del Perú. Ver MELÉNDEZ, J., Tesoros Verdaderos De Las Yndias en la Historia de la gran provincia de San Juan Bautista del Perú de el Orden de Predicadores, Roma, Nicolás Ángel Tinassio, 1682, Vol. III, pp. 697-716.

12 BARBOSA MACHADO, D., Bibliotheca lusitana historica, critica e cronologica, Vol. IV, Lisboa, Ignacio Rodrigues, 1752, p. 742. DÍAZ DÍAZ, G., Hombres y documentos de la filosofía espańola, Vol. 2, Madrid, CSIC, 1983, p. 514.

13 Cuervo seńala que nació en "Valencia de la Torre, en el maestrazgo de León, en la provincia de Extremadura", Historiadores del convento de San Esteban de Salamanca, op. cit., p. 320.

${ }^{14}$ BELTRÁN DE HEREDIA, V., Bulario de la Universidad de Salamanca (1219-1549), Vol. I, Salamanca, Universidad de Salamanca, 1966, p. 229. Más recientemente y tras una exhaustiva revisión de la documentación relativa a la matriculación de estudiantes portugueses entre los siglos XVI y mediados del XVII, Marcos de Dios consideró a Chaves como la quinta ciudad portuguesa que más estudiantes envió a Salamanca (después de Lisboa, Guarda, Vila Real y Braganza), MARCOS DE DIOS, Á., "Portugueses en la Universidad de Salamanca en la Edad Moderna”, en: RODRÍGUEZ SAN PEDRO-BEZARES, L. E. (ed.), Historia de la Universidad de Salamanca, III. 2: Saberes y confluencias, Salamanca, Universidad de Salamanca, 2006, pp. 1101-1128, cit. p. 116.

${ }^{15}$ Véase Díaz Díaz, basándose en Quétif-Echard, Silva y Fraile, Hombres y documentos de la filosofía española, Vol. 2, op. cit., pp. 514-515. 
pirla relativamente pronto. En la década de 1540 lo encontramos como uno de los "famosos predicadores" enviados desde Salamanca y Valladolid a Medina de Rioseco para consolidar el nuevo convento dominicano de San Pedro Mártir, fundado en $1543^{16}$. Teniendo en cuenta que Medina de Rioseco es un nombre capital en la historia del iluminismo y del cripto-protestantismo español -sabemos que un grupo de "doce apóstoles" que predicaban ideas heterodoxas en Medina fue desmantelado por la Inquisición española a principios de la década de $1530^{17}$-, podemos considerar la misión asignada a Chaves como parte de las iniciativas planteadas por los dominicos o encomendadas a la Orden de Predicadores para evitar cualquier tipo de contagio protestante en Castilla.

No sabemos exactamente cuánto tiempo estuvo Tomás de Chaves en Medina de Rioseco. A mediados de la década de 1550 figura entre los dominicos del convento de San Gregorio de Valladolid encargados de examinar y corregir una edición de los sermones de Savonarola traducidos del italiano al latín por Alonso Muñoz, más conocido por su importante labor en la posterior edición de las Relecciones de Vitoria ${ }^{18}$. Chaves continuó ejerciendo esta labor de revisor y censor en años sucesivos. Por encargo de sus superiores en la Orden de Predicadores, revisó y aprobó también en 1565, junto al mismo Alonso Muñoz y a Tomás de Pedroche, prior del convento dominico de Toledo, el importante Lexicon ecclesiasticum latino hispanicum de Diego Ximénez Arias ${ }^{19}$, cuya primera edición fue publicada en Salamanca en $1566^{20}$.

Pese a que su labor como examinador de obras teológicas demuestra el relativo peso y reconocimiento intelectual que Tomás de Chaves llegó a alcanzar en la orden dominica, la información relativa a sus estudios no se aviene totalmente al tipo de

${ }^{16}$ HOYOS, M. de los, Registro historial de la provincia de Espańa, Segunda parte, Tomo I, Conventos de la Primera Orden, Madrid, 1966, p. 76.

${ }_{17}$ Una perspectiva reciente sobre este grupo en PASTORE, S., Una herejía española. Conversos, alumbrados e Inquisición (1449-1559), Madrid, Marcial Pons, 2010, pp. 165-238.

18 " [...] el qual dicho libro parece auer visto y examinado los muy reuerendos padres fray Thomas de Chaues Presentado, y fray Francisco de Tordesillas del conuento de san Pablo de Valladolid, y por otras personas desta uniuersidad de toda erudición y christiandad", Carta de Don Pedro de Yllanes, vicario general en la ciudad y obispado de Salamanca, 17 de agosto de 1556. En: SAVONAROLA, G., Homiliae, Salamanca, Juan de Canova, 1556, [s.p.]. Sobre esta edición, ver BELTRÁN DE HEREDIA, V., "Las corrientes de espiritualidad entre los dominicos de Castilla”, en: BELTRÁN DE HEREDIA, V., Miscelánea Beltrán de Heredia, Salamanca, OPE, 1972, pp. 519-671, espec. pp. 580-584.

19 Ver la "Copia y traslado de la licencia de la orden para imprimir esta obra, confirmada por el muy Reverendo Padre el Maestro Fray Juan Salinas, Provincial, successor de quien la dio [fray Cristóbal de Córdoba]” seguida de la "Aprovacion" firmada por Pedroche, Muńoz y Chaves (quien firma, nuevamente, como "Presentado"), presente en las múltiples ediciones de la obra. Hemos consultado la edición publicada en Barcelona por Sebastián de Cormellas (1613).

${ }^{20}$ XIMÉNEZ ARIAS, D., Lexicon ecclesiasticum latinohispanicum ex sacris Bliblijs Conciliis, Pontificum ac theologorum decretis, divorum vitis, varijs Dictionarijs, aliisque probatissimis scriptoribus concinnatum, Salamanca, Andrea de Portonaris, 1566. 
responsabilidades que se le encomendaban. Hasta su muerte en 1570, casi cuarenta ańos después de asistir a los cursos de Vitoria, no parece que Chaves hiciera ningún progreso 'oficial' y certificado en su carrera académica. Firma, de hecho, las diferentes ediciones del libro como "padre presentado", título que indica que, aunque "presentado" por la orden dominicana para realizar sus estudios y obtener títulos universitarios ${ }^{21}$-maestro, doctor- no llegó a obtenerlos ${ }^{22}$. No hay menciones a Tomás de Chaves en la documentación relativa a la obtención de los grados de "licenciado" y "maestro" en la Facultad de Teología de la Universidad de Salamanca. Tampoco aparece como catedrático [propietario o sustituto], ni como candidato a ocupar cátedras en las fuentes que se conservan sobre las oposiciones a cátedras vacantes $^{23}$. Todo indica, por tanto, que, a diferencia de otros discípulos de Vitoria, Tomás de Chaves nunca llegó a ejercer la docencia en la Universidad de Salamanca antes de su muerte en $1570^{24}$.

Aparte de las cartas prefatorias incluidas en las distintas ediciones de la Summa sacramentorum y el Confessionario, el contenido de ambos libros no proporciona muchas informaciones sobre la vida y la trayectoria intelectual de Chaves. La Summa sacramentorum contiene sólo una referencia biográfica y no tiene que ver con Chaves sino con Vitoria, quien en varias de sus lecciones sobre la Summa theologiae y el $I V$ de las Sentencias se refirió a algunos de los casos que evaluó durante la breve estancia que realizó en Flandes en torno a $15222^{25}$.

${ }^{21}$ Al haber sido presentados por su orden, la Universidad eximía a los "padres presentados" de la obtención del título de bachiller, permitiéndoles aspirar a los títulos de licenciado y maestro, RAMÍREZ GONZÁLEZ, C. I., Grupos de poder clerical en las universidades hispánicas. Volumen 2, Los regulares en Salamanca y México durante el siglo XVI, México, UNAM, 2002, p. 43.

${ }^{22}$ Chaves es presentado aún como Padre presentado en la portada de la última edición de la Summa sacramentorum publicada durante su vida, VITORIA, F. de, CHAVES, T. de, Summa Sacramentorum Ecclesiae, ex doctrina Fratris Francisci Victoria, ordinis Praedicatorum apud Salmanticam olim Primarij Cathedratici, Per Reverendum patrem Praesentatum Fratrem Thomam à Chaues illius discipulum, Salamanca, Domingo de Portonaris, 1570 .

${ }^{23}$ Informaciones detalladas sobre las personas que obtuvieron títulos y participaron en concursos de cátedras vacantes en la Facultad de Teología de la Universidad de Salamanca en RAMÍREZ GONZÁLEZ, C. I., La Universidad de Salamanca en el siglo XVI. Corporación académica y poderes eclesiásticos, Salamanca, Universidad de Salamanca, 2002, pp. 370-393.

${ }^{24}$ MARIETA, Juan de, Historia Eclesiástica de todos los santos, de Espańa. Segunda parte, Cuenca, Pedro del Valle, 1596, f. 211r; QUÉTIF, Jacques / ECHARD, Jacques, Scriptores ordinis praedicatorum, París, Ballard / Simart, 1721, t. II, p. 192.

${ }^{25}$ Se trata de una interesante referencia a un caso de matrimonio "entre personas ilegítimas" en el que él mismo Vitoria habría intervenido como asesor teológico y jurídico, confrontando su opinión a la de varios juristas. "QVÆritur, vtrum si sponsalia contrahantur inter personas illegitimas, animo contrahendi sub hac conditione, si papa dispensauerit, an adueniente conditione sint vera sponsalia? \& si fuerunt verba de præsenti, an sit matrimonium conditione adueniente? Et augeatur dubium, ponamus quod isti postquam venit dispensatio habeant eam ratam. In Flandria fuit mihi magna controuersia cum aliquibus iuristis super isto casu. Sed respondeo, quod non est matrimonium \& oppositum est error intolerabilis". Hemos seguido la edición vallisoletana de 
Contrariamente a los diversos episodios de la vida de Tomás de Chaves entre la década de 1530 y finales de la década de 1550 que aún cabe clarificar, contamos con algunas informaciones precisas sobre el lugar en el que residía cuando se ocupó de dar los últimos retoques a la Summa sacramentorum e impulsar su publicación. De acuerdo a uno de los documentos prefatorios incluidos en la primera edición de la obra, el 15 de junio de 1558, al dar licencia al "reverendo señor Antonio de Lantadilla Vela clerigo de Burgos" ${ }^{26}$, para que se encargara de los trámites de la edición en Valladolid, se encontraba "en el monasterio de sant Pablo de Burgos de la orden de los predicadores" ${ }^{27}$. Chaves daba asímismo "fee y testimonio que esta suma de los siete sacramentos, que yo saque agno de mil y quinientos y quarenta y uno de las lectiones y doctrina que el sapientissimo y de perpetua memoria digno fray Francisco de Victoria maestro cathedratico de prima de Salamanca y preceptor mio, toda fue tomada de su doctrina, y del mesmo maestro a mi petición vista y aprobada" ${ }^{28}$. Este testimonio constituye la verdadera sustancia de un documento prefatorio incorporado a la Summa sacramentorum para facilitar, ante todo, su aprobación por los censores de la orden y hacerla, además, más atractiva en el mercado editorial de la época.

\section{Rescate del proyecto aparcado de la Summa sacramentorum en el Capítulo provincial de 1559. La autoridad de un Vitoria redivivus frente a los Comentarios al catecismo cristiano de Carranza (1558).}

EN ABRIL DE I 559 tuvo lugar en Segovia un Capítulo provincial de gran importancia para la orden dominica. Además de reelegir por unanimidad a Melchor Cano como provincial de los dominicos espańoles, contrariando la voluntad de Carranza ${ }^{29}$, los definidores del capítulo dieron también un impulso significativo a la publicación de

1561, "reimpresión" de la princeps de 1560, VITORIA, F. de; CHAVES, T. de, Summa sacramentorum, Valladolid, Sebastián Martínez, 1561, f. 183v. Ofrecen noticias de este viaje a Flandes varias de las reconstrucciones de la vida de Vitoria: BELTRÁN DE HEREDIA, V., Los manuscritos del maestro fray Francisco de Vitoria, Biblioteca de Tomistas Espańoles, Madrid / Valencia, 1928, p. 3; CASTILLA URBANO, F., El pensamiento de Francisco de Vitoria. Filosofía política e indio americano, Barcelona / México, Anthropos / UAM Iztapalapa, 1992 , p. 364.

${ }^{26}$ Residente en Valladolid como capellán de Juan Sarmiento, comisario general de la Santa Cruzada y oidor del Consejo de Indias, según indica el mismo documento prefatorio.

${ }^{27}$ CHAVES, T. de, "Testimonio que esta summa de los siete sacramentos [...] toda fue tomada de su doctrina", 15 de junio de 1558, en: VITORIA, F. de, CHAVES, T. de, Summa Sacramentorum Ecclesiae (1561), op. cit., [s.p.].

28 Ibid.

${ }^{29}$ En su biografía sobre Melchor Cano, Fermín Caballero confundió a Tomás de Chaves con Diego de Chaves, indicando que Tomás de Chaves había sido la persona a la que los definidores del capítulo encargaron comunicar su decisión final a Carranza, CABALLERO, F., Vida del Illmo. Sr. D. Fray Melchor Cano, del orden 
la Summa sacramentorum ${ }^{30}$, que quizás convendría entender también como parte de la campaña desatada contra las ideas religiosas de Carranza. Teniendo en cuenta que, por aquel entonces, Cano y un nutrido grupo de dominicos trataban de atacar y frenar con diversas iniciativas la repercusión que pudieran llegar a tener los Comentarios sobre el catecismo cristiano que Carranza había publicado en $1558^{31}$, el apoyo concedido a la Summa sacramentorum justo en este momento podría considerarse como una iniciativa común de los dominicos anti-carrancistas por oponer a los Comentarios -en especial a su tercera parte, dedicada a los sacramentos- un material catequético y pastoral cuya ortodoxia fuera indudable. Con esta finalidad en mente, ningún material podía resultar más útil e interesante que una suma de sacramentos extraída de las lecciones del maestro de maestros, Francisco de Vitoria, y aprobada, según afirmaba Tomás de Chaves, por el mismo maestro.

En este sentido, aunque no parece que Tomás de Chaves fuera uno de los dominicos coludidos en la persecución contra Carranza, pues no sólo firmo una aprobación de los Comentarios al catecismo a finales de $1559^{32}$, sino que también se le menciona en el proceso contra el arzobispo como una de las personas que lo frecuentaba $^{33}$, su proyecto de edición de un compendio o epítome de las lecciones de

de Santo Domingo, obispo de Canarias, etc., Madrid, Imprenta del Colegio Nacional de Sordo-Mudos y de Ciegos, 1871, p. 113. Caballero extrajo esta información de una carta escrita por Carranza a los definidores dominicos el 24 de abril de 1559, poco después de concluir el Capítulo: "Muy Reverendos Padres: Con el P. M. Chaves recibí las de Vuestras Paternidades, y él me dijo la satisfaccion que allá se había tomado de la queja, que de nuestra parte propuso Fr. Diego Ximenez, y no fue como la gravedad del negocio lo requeria [...]". Carta transcrita en Ibid., p. 618. Como indica el tratamiento de maestro dado a este Chaves por Carranza, Caballero incurrió en un error y confundió a Tomás de Chaves con el Maestro Diego de Chaves. Lo confirma, además, un documento firmado por el mismo Diego de Chaves, entregado por él mismo a Carranza, en la que testifica que durante el capítulo de Segovia, Melchor Cano juró no haber dicho "al Almirante de Castilla que el Arzobispo de Toledo era mayor hereje que Lutero e que ponía en disputa las cosas de la fe como era dudar de la perpetua virginidad de Nuestra Senora e que favorescía a los que estaban presos por la Inquisición”, CHAVES, Diego de, "Testimonio en nombre del Capítulo de Segovia", 24 de abril de 1559, en TELLECHEA IDÍGORAS, J. I., Bartolomé Carranza. Estudios Completos II: El trauma nacional religioso de 1558-1559: estudio y epistolario, A Coruña, Mendaur, 2019, doc. 261.

30 En las primeras ediciones de la Summa se incluye una "Licencia de la Orden" escrita en Segovia el 22 de abril de 1559 y firmada por Juan de Ludeńa, Domingo Calvete, Cristóbal de Salamanca y Martín de Ayllón, es decir, los mismos definidores del capítulo que decidieron reelegir a Cano y apoyarlo en su pugna contra Carranza.

31 CARRANZA, B. de, Comentarios sobre el catecismo cristiano, Amberes, Martín Nucio, 1558.

32 Chaves escribió su aprobación desde el convento de San Pablo de Burgos, donde seguía residiendo. Con excepción de un matiz nimio, consideró la doctrina de los Comentarios sobre el catecismo como "sana, santa y segura": "Vi este tratado, y su doctrina es sana, santa y segura, sino es renglón y medio que borré en el primer artículo de la humanidad do decia que los ángeles que cayeron, asistían á Dios y miraban siempre su rostro: lo cual es falso porque si una vez lo vieran no se podían perder. Y porque esto es mi parecer, lo firmé de mi nombre en San Pablo de Burgos á treinta de diciembre de 1559. Fray Tomás de Chaves”, SÁINZ DE BARANDA, P., Noticia sobre la vida de D. Fr. Bartolomé Carranza de Miranda, Arzobispo de Toledo, Madrid, Viuda de Calero, 1845 , p. 129.

33 De acuerdo a la declaración que el licenciado Osorio, criado de Carranza, hizo en Madrid el 22 de septiembre de 1562 ante el juez Gaspar de Zúñiga. TELLECHEA IDÍGORAS, J. I. (ed.), Fray Bartolomé de Carranza. 
Vitoria sobre teología sacramental -impartidas a modo de comentario al IV de las Sentencias de Pedro Lombardo- pudo verse favorecido por las complejas circunstancias por las que atravesaba en ese momento la orden dominica.

\section{El manuscrito MSS/49 de la Biblioteca Pública del Estado en Cáceres, prueba de un proyecto de edición abortado de las lecciones In IV Sent en vida de Francisco de Vitoria (1541).}

Como ya mencionamos, el 15 de junio de 1558 Tomás de Chaves escribió una declaración firmada indicando que su Summa sacramentorum era un material que él mismo había "sacado" de las lecciones de Vitoria sobre los sacramentos. Chaves iba incluso más allá y afirmaba con rotundidad que la obra, que se encontraba concluida ya en 1541, "toda fue tomada de su doctrina, y del mesmo maestro a mi petición vista y aprobada” 34 . Tradicionalmente, la historiografía ha visto con desconfianza esta afirmación de Chaves. Luis Alonso Getino insistió, por ejemplo, en no tener en cuenta ni la Summa sacramentorum ni el Confessionario como parte de los escritos de Vitoria ${ }^{35}$ y consideró que los títulos de ambos libros, atribuyéndolos a Vitoria, no eran más que una estrategia de marketing. No entendiendo muy bien el carácter funcional y pragmático de este tipo de epítomes, Teófilo Urdanoz llegó a atacar ferozmente al 'oportunista' Chaves, denunciando que en su obra sobre los sacramentos "acortaba demasiado la obra vitoriana, eliminando todas las cuestiones teóricas y sutilezas de acuerdo con la intención didáctica y el método pedagógico del manual" ${ }^{36}$. Incluso escritos recientes sobre Vitoria reflejan aún una mirada crítica a ambos libros, considerados "más una reflexión que una réplica exacta del pensamiento de Vitoria" ${ }^{37}$.

Aunque no es posible probar al completo las declaraciones de Chaves, pues no contamos con otros testimonios de la época dando fe de que el contenido de la Summa llegara a ser leído y aprobado por Vitoria, hay elementos más que sufi-

Documentos históricos. III Testificaciones de abonos, indirectas y tachas, Madrid, Real Academia de la Historia, 1966, p. 505.

${ }^{34}$ CHAVES, T. de, "Testimonio que esta summa de los siete sacramentos [...] toda fue tomada de su doctrina", 15 de junio de 1558, en: Vitoria, F. de, Chaves, T. de, Summa Sacramentorum Ecclesiae (1561), op. cit., [s.p.].

${ }^{35}$ ALONSO GETINO, L., El maestro Fr. Francisco de Vitoria: su vida, su doctrina e influencia, Madrid, Asociación Francisco de Vitoria, 1930, pp. 335-338.

${ }^{36}$ URDÁNOZ, T., "Introducción”, en: Vitoria, F. de, Urdánoz, T. (ed.), Obras de Francisco de Vitoria: relecciones teológicas, Madrid, BAC, 1960, p. 28.

${ }^{37}$ CASTILLA URBANO, F., El pensamiento de Francisco de Vitoria. Filosofía política e indio americano, op. cit., p. 344. 
cientes para corroborar el resto de sus afirmaciones, a saber, que el material fue elaborado en 1541 y que refleja con mucha fidelidad el contenido de las lecciones dedicadas por el maestro a la materia de los sacramentos.

El manuscrito MSS/49 de la Biblioteca Pública del Estado en Cáceres, procedente de la rica librería atesorada por el Convento de San Benito de Alcántara entre los siglos XVI y XVIII prueba, de hecho, no sólo que la Summa sacramentorum fue redactada en 1541, sino que la obra se encontraba lista o casi lista para ser impresa en esta fecha ${ }^{38}$. Se trata de un manuscrito importante para entender la circulación manuscrita de las ideas de Vitoria, iniciada ya en los años finales de su vida, que hasta ahora no había sido estudiado ni mencionado en ninguna publicación académica.

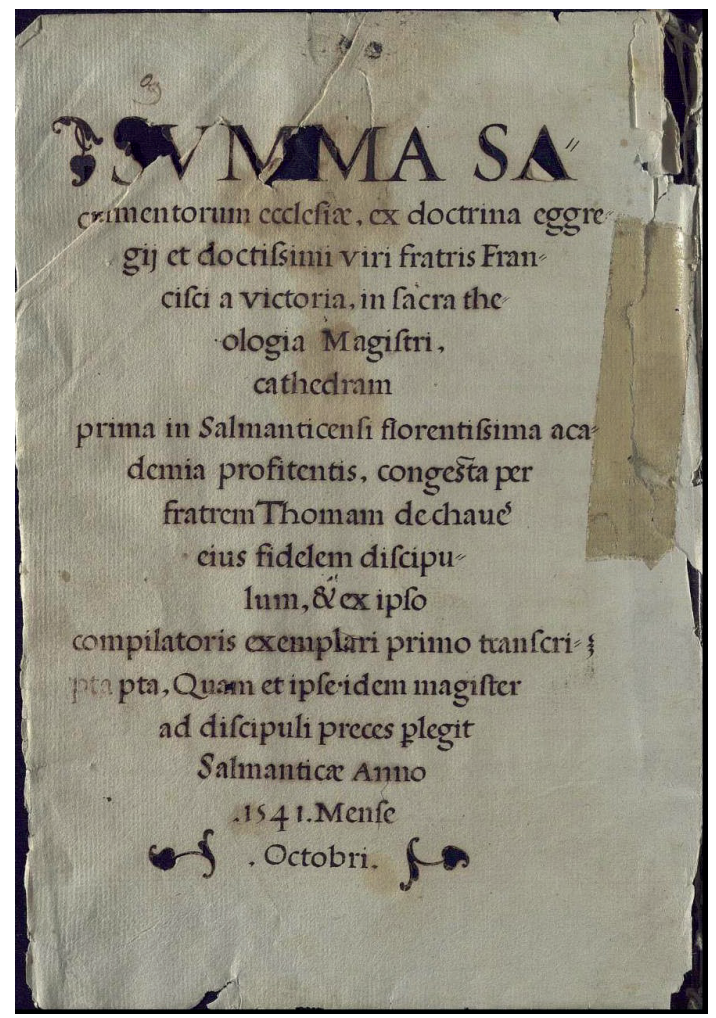

Figura 1. Portada. MSS/49, Biblioteca Pública del Estado

A. Rodríguez-Moñino/M. Brey (BPE), Cáceres.

\footnotetext{
${ }^{38}$ MSS/49, Cáceres. Biblioteca Pública del Estado "A. Rodríguez-Moñino/M. Brey". Indicaciones de clasificación anterior en la parte superior de la cubierta del manuscrito, "Cajon 126".
} 
El título del documento, en letras manuscritas que imitan las letras de molde de la imprenta reza: Summa sacramentorum ecclesiae, ex doctrina eggregij et doctissimi viri fratris Francisci a victoria, in sacra theologia Magistri, cathedram prima in Salmanticensi florentissima academia profitentis, congesta per fratrem Thomam de chaves eius fidelem discipulum, \& ex ipso compilatoris exemplari primo transcripta, Quam et ipse idem magister ad discipuli preces perlegit Salmanticae Anno 1541. Mense Octobri (ver Figura 1).

El contenido del manuscrito es muy cercano a la Summa impresa de 1560. El cuerpo central del texto manuscrito, extraído de las lecciones de Vitoria, se mantiene sin grandes alteraciones en la primera edición de la Summa. Los pequeños cambios introducidos entre la redacción de este manuscrito que, como reza su portada, sería una copia realizada a partir del ejemplar compilado y redactado por el propio Chaves en Salamanca en 1541, y el texto impreso en 1560 afectan de forma desigual a las distintas secciones de la obra. Se aprecian más, por ejemplo, al comienzo de la primera parte, dedicada al tratamiento del tema "De Sacramentis in communi" ${ }^{39}$ que en los parágrafos dedicados al sacramento del matrimonio, prácticamente idénticos en ambos textos ${ }^{40}$.

Que el ejemplar personal de Chaves del que deriva la copia contenida en este MSS/49 estaba ya casi listo para su publicación como obra impresa lo atestigua el hecho de que tanto la carta en la que Chaves dedica la obra a Francisco Pérez, rector de la iglesia toledana de San Ginés ${ }^{41}$, como la "Tabula questionum et articulorum" se encuentren en ambos documentos ${ }^{42}$. El contraste entre los índices presentes en el manuscrito y la edición vallisoletana de 1560-61 viene también a confirmar la cercanía entre ambos textos, muy similares, aunque no completamente idénticos. En algún momento entre 1541 y 1558 Chaves debió, por tanto, revisar la Summa y ampliar el índice para incluir algunas cuestiones no referidas en la "Tabula quaestionem et articulorum" original. Se trata, en todo caso, de cuestiones que, abordabas en ambos textos, reciben en el texto impreso el tratamiento de cuestiones o artículos en sí mismos, mientras que en el manuscrito

\footnotetext{
39 VITORIA, F. de, CHAVES, T. de, Summa Sacramentorum Ecclesiae (1561), op. cit., ff. 1r-5r; MSS/49, ff. $4 \mathrm{r}-5 \mathrm{v}$.

${ }^{40}$ VITORIA, F. de, CHAVES, T. de, Summa Sacramentorum Ecclesiae (1561), op. cit., ff. 173v-209r; MSS/49, ff. $76 \mathrm{v}-92 \mathrm{v}$.

${ }^{41}$ CHAVES, T. de, "Admodum reverendo domino Francisco Perez, ecclesiae Toletanae sancti Genesij rectori, frater Thomas de Chaves", VITORIA, F. de, CHAVES, T. de, Summa Sacramentorum Ecclesiae (1561), op. cit., [s.f.]; MSS/49, ff. 3r-3v.

${ }^{42}$ CHAVES, T. de, "Tabula. Sequitur Tabula quaestionem \& articulorum in hac summa contentorum”, Vitoria, F. de, Chaves, T. de, Summa Sacramentorum Ecclesiae (1561), op. cit., ff. 250r [246r]-[258v]; "Tabula quaestionem et articulorum in hac summa contentorum", MSS/49; ff. 93r-97v.
} 
aparecen subsumidos como parte de otros artículos ${ }^{43}$. En el tratamiento de la materia De sacramentis in genere ese es el caso de las cuestiones "Sacramentorum sufficientia" y "Promulgatio evangelij, quando fuit facta sufficienter", no mencionadas en el índice de cuestiones del manuscrito (ver Figuras 2 y 3 ) pero abordadas en los ff. 5r. y 7r (a partir de la segunda línea) del mismo. Las líneas finales de este último artículo difieren entre manuscrito e impreso por lo que, al igual que las frases con las que se abre la obra y otros pasajes del texto, debieron ser revisadas por Chaves después de 1541.

Otra posibilidad es que fueran el impresor Sebastián Martínez o el clérigo Antonio de Lantadilla Vela, a quien como dijimos, comisionó Chaves para que se encargara de los trámites relativos a la impresión de la obra, quienes llevaran a cabo estas modificaciones tardías. Ambos se tomaron, en efecto, la libertad de escribir cartas prefatorias a la Summa sacramentorum. Mientras que Sebastián Martínez aprovechó la ocasión para felicitar a Francisco Manrique de Lara por la reciente obtención del rico obispado de Sigüenza (1560) y dedicarle una obra que atribuía totalmente al maestro Vitoria ${ }^{44}$, Antonio de Lantadilla intervino para recomendar la obra al "Pío lector", aunque repartiendo sus alabanzas entre el "celebratissimum in universa Europa" Vitoria y el menos conocido, aunque "peritissimun" en teología, Tomás de Chaves. Su carta es importante en la medida en que refleja su participación como revisor y corrector de la obra ${ }^{45}$. Lantadilla es, por otra parte, un personaje crucial en esa red de comerciantes burgaleses cuyas actividades e intereses resultan tan importantes para entender el contexto familiar y de gestación del pensamiento de Vitoria sobre asuntos prácticos y que, como

43 En el manuscrito el texto aparece dividido en Artículos, separados por un espacio, y numerados con ordinales en cifras arábigas. La numeración (Articulus Primus (19), Secundus (29),...) comienza de nuevo cada vez que el autor pasa a abordar un nuevo sacramento. En el texto impreso los artículos y cuestiones siguen una misma numeración (del 1 al 281) y comienzan con el el símbolo $\$$ seguido de las dos o tres primeras letras del texto del artículo en mayúscula. Por ejemplo, en el último artículo abordado por ambos textos: "281. \$COgnatio legalis contrahitur per hoc quod quis adoptat sibi filium", f. 208r. "Ar9 649. De cognatione legali quando contrahitur per hoc quod quis adoptat sibi filium”, f. 92v.

44 "Elaborauit igitur opus certe aureum frater Franciscus de Victoria, sine cuiusquam iniuria suae tempestatis theologorum doctissimus, quod licet per se satis lectu dignum, \& ex manibus auditorum (qui modo vellint aliquid verae theologiae adipisci) excidere non debeat, intellexi tamen tutius fore (quo canum latratus effugiat) si tibi insigni praesulum ornamento dedicarem", MARTÍNEZ, S., "Illustrissimo ac reverendissimo domino. D. Francisco Manrrico de Lara Episcopo Seguntino \& c.”, VITORIA, F. de, CHAVES, T. de, Summa Sacramentorum Ecclesiae (1561), op. cit., [s.p.].

${ }^{45}$ Lo subrayan el título de su epístola prefatoria y los detalles que da en la misma sobre su grado de participación en la obra. "Vbi tam plene, cumulateque omnia inuenies, quae requires, quaeque ad hanc doctrinam exiguntur ut nullus sit quantumuis mentis inops, qui eo accurate lecto \& inspecto, non possit sacramenta ipsa administrare, pastorisque munus (modo industria \& solertia comités ad sint) sustinere", LANTADILLA VELA, A. de, "Pio lectori. Antonius de Lantadilla Vela qui in huius edictione elauorauit. S. P. D.", in VITORIA, F. de, CHAVES, T. de, Summa Sacramentorum Ecclesiae (1561), op. cit., [s.p.]. 


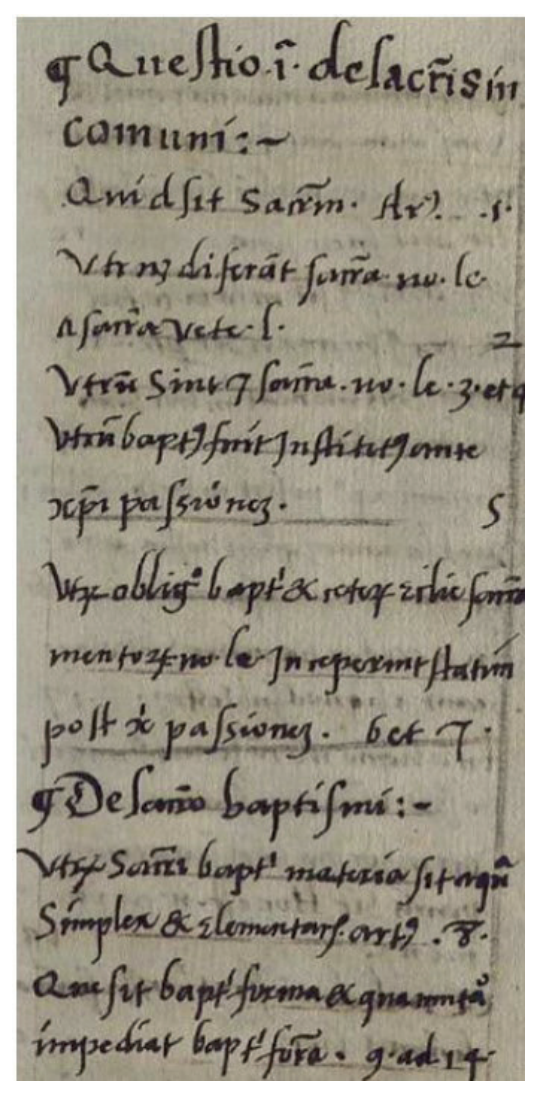

Figura 2. MSS/49, BPE Cáceres, f. 93r.
Tabula. $25^{\circ}$

Sequitur Tabula quxitionum \& ar: ticulorum in hac fumna contentorum.

C2urefio.t.de facramentis in cöi,quid fic facramentum. fo. t.pagina.t.numero.t.

CVtrum differant facramenta noux legis a facra'nentis veteris legis fo.2.pa.2.n.2.

C V trum fint feptem facramenta noux legis. fo.3.pa.2.nume.3.

CS : c amentorum fufficientia.f.4.p. 1.n.4.

(C) $V$ trm baptifnus fuerit inltitutus ante Chrifti pafsionem.fo.s.pag, 2.nnme.s.

CVtuin obligatio baptifmi,\& aliorum a cranientorum noux legis incoperit ftatim poft Chriftũ paffum.fo.6.p.2.nu.7. CPromulgatio enangelijquando fuit tacta fufficientér. fo.8.pa.2.numc.8. Debaptifmo

CVtrū materia baptifmi fit aqua fimplex \& elementaris.fo.9.pa.2.numie.9. ๔Qux fit forma baptifmi fo.\& pa.ca.n.10. II unx mutatio impediat baptifmi formä. fo.10.pa.l. nume.11.

$\underset{\text { CVtrum baptifmus in nomine Chriftife }}{\text { validus }}$

Figura 3.Vitoria, F. de, Chaves, T. de, Summa sacramentorum ecclesiae, Valladolid, Sebastián Martínez, 1561, f. 250r.

vemos, una vez muerto el maestro, se esforzó para que la obra de su conciudadano no quedara en el olvido ${ }^{46}$.

Las cartas prefatorias de Sebastián Martínez y Antonio Lantadilla no se encuentran en el manuscrito de la Summa sacramentorum conservado en Cáceres, aunque

\footnotetext{
${ }_{46}$ Jurista, obtuvo el doctorado en derecho civil y canónico en el Colegio de los Espańoles de Bolonia, del que llegó a ser rector, en 1547. Su familia estaba ligada a los dominicos burgaleses desde tiempo atrás, siendo los Lantadilla patronos de la capilla de Santiago en ese convento de San Pablo donde Tomás de Chaves residía, JONES MATHERS, C., "Students from Burgos at the Spanish College at Bologna (1500-1560)", The Sixteenth Century Journal 18:4 (Winter, 1987), pp. 545-556, espec. pp. 550, 553, https://doi.org/10.2307/2540869; VELASCO Y HERRERA, S. S. de, Compendio de la nobilissima fundacion y privilegios del Colegio Mayor de Señor S. Clemente de los espańoles de Bolonia, [Sevilla], Juan Francisco de Blas, 1695, p. 61.
} 
sí la escrita por Tomás de Chaves para dedicar la obra al clérigo toledano Francisco Pérez. Tampoco se encuentran el privilegio de impresión regio y las licencias favorables concedidas por los definidores del Capítulo provincial de Segovia (22 de abril de 1559) y por el experto a quienes le encargaron examinar la obra (el Prior de San Pablo de Valladolid, Juan de Ludeńa, juez y parte en este asunto, pues también ejerció como definidor en el Capítulo). Además de estos documentos oficiales, necesarios en la época para que una obra de este tipo pudiera llegar a imprimirse, el tratado publicado en 1560 incorporó dos capítulos finales no contenidos en el manuscrito MSS/49 de Cáceres: un Tractatus de clavibus y un Tractactus de excommunicatione $^{47}$, indirectamente ligados a los temas de teología sacramental abordados en la Summa sacramentorum. No está claro si estos materiales son también epítomes de lecciones dictadas por Vitoria. Para resolver la duda habría que proceder a contrastar con detenimiento su contenido con los manuscritos de las lecciones de Vitoria en las que aborda las materias de la potestad eclesiástica y la excomunión, tarea de la que me ocuparé en otra ocasión. Desde la primera edición del libro, Chaves parece mostrar en estos dos tratados un criterio más independiente con respecto al pensamiento de Vitoria, que, a diferencia de lo que acontece en las partes anteriores de la Summa sacramentorum, reporta en estilo indirecto.

Aunque son muchos los aspectos que faltan por investigar, el contraste entre el manuscrito cacereño MSS/49 y la primera edición de la Summa sacramentorum (1560-61), revela claramente la existencia de un primer proyecto de publicación del libro, a ubicar con toda seguridad antes de 1558, momento en el que comienzan las gestiones que dieron lugar a su publicación definitiva. Aunque no contamos con una certeza absoluta, es muy probable que este proyecto inicial remonte al período 1539-41, fechas en las que, por una parte, Chaves afirma que la Summa sacramentorum fue redactada y en las que, por otro lado, y como han apuntado diversos estudiosos, Vitoria dedicó algún tiempo a preparar sus comentarios al $I V d e$ las Sentencias con el fin de que pudieran ser impresos. Lamentablemente, no pudo concluir esta tarea dado el delicado estado de salud en el que se encontraba en esta fase de su vida ${ }^{48}$.

El manuscrito MSS/49 de la BPE de Cáceres, clave para responder a algunas de las dudas sobre la contribución de Tomás de Chaves a la impresión de las leccio-

\footnotetext{
${ }^{47}$ Como se aprecia, por ejemplo, en la respuesta a la duda acerca de si resulta vinculante una sentencia de excomunión ignorada por su destinatario: "Et quamuis sapientissimus magister á Victoria in neutram partem aperte declinet, tamen primam sententiam reputat tutiorem. Et ideó tenendum est, quod si fiat id pro quo lata est formalitèr excommunicatio incurritur, esto inuincibilitèr ignoretur ius", VITORIA, F. de, CHAVES, T. de, Summa Sacramentorum Ecclesiae (1561), op. cit., f. 235v.

${ }^{48}$ BELTRÁN DE HEREDIA, V., Los manuscritos del maestro fray Francisco de Vitoria, op. cit., p. 27-28; COUJOU, J. P., ZORROZA, M. I., Bibliografía vitoriana, Pamplona, EUNSA, 2014, p. 36.
} 
nes de Vitoria sobre los sacramentos, abre a su vez nuevos interrogantes sobre un primer proyecto de publicación aplazado durante veinte ańos por razones que aún ignoramos: ¿Están relacionados el epítome de Chaves y la labor realizada por el propio Vitoria para que sus lecciones In IV Sent pudieran imprimirse, o se trata de dos iniciativas independientes? ¿Pudo Chaves tener a disposición materiales escritos por el mismo Vitoria o habría sido, más bien, Vitoria el que, impedido para trabajar, se apoyó en Chaves para que dispusiera sus lecciones para la imprenta? En todo caso, ¿por qué no llegó a imprimirse este valioso material en 1541, cuando, según todos los indicios, se encontraba ya listo para ser publicado? ¿Fue aprobado el texto realmente por Vitoria o, descontento con el trabajo de Chaves no dio, en realidad, luz verde para su impresión?

Esperando contar con nuevos materiales que ayuden a despejar estas incógnitas en el futuro, pasamos a contrastar a continuación el contenido del manuscrito MSS/49 de la BPE de Cáceres con los manuscritos de la biblioteca de Ajuda (Lisboa), Ms. 44-XII-20, ff. 463-696, y de la Biblioteca Nacional de España, MSS/13923, los dos manuscritos que hasta la fecha habían sido relacionados con las lecciones dedicadas por Francisco de Vitoria al IV de las Sentencias.

\section{El MSS/49 (BPE, Cáceres) y el MSS/13923 (BNE, Madrid), dos manuscritos gemelos, testimonio de la intensa circulación manuscrita del epítome de Chaves.}

A Diferencia de LAS LeCCIONES sobre la Summa theologiae, de las que diversos especialistas en la obra de Vitoria han localizado y estudiado decenas de manuscritos, las lecciones que el maestro dedicó al $I V$ de las Sentencias en los cursos 1529-31 y 1538-39 están mucho menos documentadas ${ }^{49}$, circunstancia que, sin duda alguna, ha influido en la escasa atención concedida a la teología sacramental en la historiografía sobre Vitoria.

Además del MSS/49 de la BPE de Cáceres que presentamos, por vez primera, en este artículo, existen al menos otros dos importantes manuscritos derivados de los comentarios de Vitoria al $I V$ de las Sentencias. Se conservan en la biblioteca de Ajuda (Ms. 44-XII-20, ff. 463-696) y la Biblioteca Nacional de España $(\mathrm{MSS} / 13923)^{50}$. Ambos manuscritos, ya mencionados en los trabajos archivísticos

\footnotetext{
${ }^{49}$ COUJOU, J. P., ZORROZA, M. I., Bibliografía vitoriana, op. cit., pp. 37-38.

${ }^{50}$ VITORIA, F. de, [CHAVES, Tomás de], Scholia magistri Francisci a Vitoria in compendium redacta super 4um librum Sententiarum, Madrid, Biblioteca Nacional de Espana (BNE), MSS/13923, ff. 1r-215v.
} 
pioneros de Beltrán de Heredia (1928) ${ }^{51}$ han sido estudiados recientemente por Lidia Lanza y Marco Toste en una valiosa y detallada perspectiva de conjunto sobre los comentarios a las Sentencias de Pedro Lombardo redactados en el ámbito ibérico durante el siglo XVI ${ }^{52}$.

Apreciando una coincidencia significativa en los argumentos y autoridades referidos en varios pasajes de los manuscritos de Lisboa y Madrid, Lanza y Toste llegaron a la conclusión de que se trata en ambos casos de materiales derivados de las lecciones de Vitoria sobre el IV de las Sentencias, aunque en el manuscrito de Lisboa, reflejo más fiel y no condensado de los cursos en Salamanca, aparecen muchas más cuestiones y "the reasoning is much more developed" 53 .

Contrastando el manuscrito que hemos hallado en la BPE de Cáceres con el MSS/13923 de la Biblioteca Nacional hemos llegado a la conclusión de que se trata de manuscritos idénticos o casi idénticos. Ciertamente, el MSS/13923 es más aseado: la letra es más cuidada y el copista utiliza menos abreviaturas. En todo caso, reproduce el mismo texto que el MSS/49 de la BPE de Cáceres y ordena del mismo modo los artículos, separándolos por un espacio y numerándolos con ordinales en cifras arábigas. A diferencia del modo en que se disponen artículos y cuestiones en la Summa sacramentorum, en ambos manuscritos la numeración comienza de nuevo cada vez que se abre la sección correspondiente a un cierto sacramento. Las únicas diferencias existentes entre ambos manuscritos y que, hasta la fecha, había confundido a los especialistas acerca del origen y la autoría del MSS/13923 de la BNE, es que este manuscrito no copia la carta con la que Tomás de Chaves dedicó la obra al clérigo Francisco Pérez ni menciona en su título la importante labor compiladora y epitomizadora realizada por el dominico. En la portada del manuscrito de la BNE figura solamente el título genérico Scholia magistri Francisci a Vitoria in compendium redacta super 4 um librum Sententiarum. Tampoco figura en el manuscrito de la BNE la "Tabula quaestionem et articulorum" que figuran en el manuscrito cacereño y en la Summa impresa.

Con respecto al cuerpo central del texto, todo lo que Beltrán de Heredia y, más recientemente, Lanza y Toste afirmaron con respecto al manuscrito MSS/13923 de la BNE se puede aplicar igualmente al MSS/49 de la BPE de Cáceres. Se trata en ambos casos de copias manuscritas de un proyecto de publicación de la Summa sacramentorum, llevado a cabo por Tomás de Chaves en torno a 1541 y que, por

\footnotetext{
51 BELTRÁN DE HEREDIA, V., Los manuscritos del maestro fray Francisco de Vitoria, op. cit., pp. 110-114.

52 LANZA, L., TOSTE, M., "The Sentences in Sixteenth-Century Iberian Scholasticism”, en: Rosemann, P. W., Mediaeval Commentaries on the Sentences of Peter Lombard, Vol. 3, Leiden, Brill, 2015, pp. 416-503, espec. 442-451. https://doi.org/10.1163/9789004283046_010

53 Ibid., pp. 447-449.
} 
razones que desconocemos aún, fue abortado inicialmente y retomado tan sólo a partir de 1558. Aunque las copias dan cuenta de un fracaso editorial, nos informan también de que, más allá del mundo del libro impreso, las lecciones de Vitoria sobre los sacramentos eran un material muy apreciado ya durante la vida del maestro y que debió circular ampliamente en forma manuscrita en el período 1541-1560, contribuyendo a dar una impronta vitoriana y salmantina al tratamiento de la teología sacramental por parte de autores radicados en diversos puntos de la Península Ibérica. Estudios posteriores deberían rastrear las obras sobre los sacramentos publicadas en este período y área geográfica para determinar el grado de influencia que los manuscritos resultantes del esfuerzo epitomizador de Chaves llegaron a ejercer en la producción teológica de su tiempo.

Una vez aclarada la filiación entre los manuscritos de Cáceres y Madrid y la Summa sacramentorum, que, con pequeñas modificaciones y haciendo excepción de las cartas y secciones añadidas, reproduce básicamente el texto contenido en ambos manuscritos, pasamos a comparar la Summa sacramentorum de 1560-61 con el manuscrito de la Biblioteca de Ajuda. Como decíamos, éste último es el único material que presenta diferencias sustanciales con respecto a la Summa sacramentorum y los dos manuscritos derivados de un manuscrito original, obra de Tomás de Chaves y correspondiente al primer intento abortado de publicar la Summa. Como han subrayado diversos expertos, frente a la forma catequética y condensada que presentan otros materiales, el manuscrito de Ajuda, que incluye muchas más cuestiones, desarrollándolas de forma extensa y resolviéndolas al modo escolástico -tras discutir una serie de argumentos pro y contra- ${ }^{54}$, sería el que reflejaría con mayor fidelidad el contenido de las clases de Vitoria y el pensamiento del maestro. Nos interesa, especialmente, comparar el manuscrito de Ajuda con la Summa sacramentorum porque, como ya apuntaban Lanza y Toste, se trata del único modo de determinar si este compendio sacramental es plenamente atribuible a Vitoria. Se trata de una tarea que, aunque abordaba hasta la fecha sólo de forma superficial, resulta fundamental para zanjar esta vieja disputa historiográfica.

\section{Condensar sin alterar. Tomás de Chaves y las labores ingratas de epitomizadores y compendiadores.}

El PAPEl DeSEMPEÑado por Tomás de Chaves en el proceso de edición de la Summa sacramentorum resulta un ejemplo muy ilustrativo del tipo de actividades intelec-

${ }^{54}$ LANZA, L., TOSTE, M., "The Sentences in Sixteenth-Century Iberian Scholasticism”, op. cit., p. 447. 
tuales emprendidas por divulgadores y epitomizadores en la Primera Modernidad. La epístola de Chaves incluida en las primeras ediciones del libro, publicadas de 1560 a 1563, no ofrecía muchos detalles sobre su contribución. El mismo Chaves se auto-relega en su intento por subrayar la paternidad vitoriana de la obra. En estas primeras ediciones, la reputación de Vitoria funciona, ciertamente, como una sólida garantía para el contenido del libro y para que éste pudiera asentarse en el mercado editorial de la época ${ }^{55}$.

Obligado por la necesidad de adaptar la Summa a las conclusiones vinculantes del Concilio de Trento (1563), y deseoso de adquirir cierto renombre con un libro muy consolidado ya entre el público lector ${ }^{56}$, a partir de la edición de 1565 Chaves se liberó un tanto de la pesada autoridad de Vitoria, suprimió la epístola en castellano, excesivamente modesta, y escribió otra ${ }^{57}$, mucho más explícita al hablar de su propio rol como epitomizador, ordenador y actualizador de las ideas de Vitoria sobre los sacramentos. Según la carta, el objetivo inicial de su trabajo había sido seleccionar los comentarios más importantes de Vitoria al IV de las Sentencias para guardarlos en forma de "tesauro eximio" ${ }^{58}$. Ahora bien, algún tiempo después de la primera edición y habiendo tenido tiempo para repensar su contenido, había decidido volver a publicarlo en una nueva edición en la que el texto pudiera presentarse totalmente "revisado, limpio, brillante y enriquecido en muchas partes". En esta nueva carta, Chaves afirma con orgullo haber "añadido muchas cuestiones importantes que antes se omitieron" y haber incluido en sus partes correspondientes muchos "decretos" y "definiciones" recientemente aprobados por el Concilio de Trento, algo importante para tranquilizar al lector sobre la ortodoxia de su doctri$\mathrm{na}^{59}$. En realidad, Chaves ya había puesto todo este empeño en la primera edición de la obra -incluso la referencia a diversos cánones aprobados por el Concilio de

\footnotetext{
55 Ya que, como insistía en subrayar Chaves, "su doctrina (como toda España, y aun la cristiandad casi toda sabe) aya sido y sea solida firme y verdadera y muy católica”, CHAVES, T. de, "Epístola de 15 de junio de 1558", en: VITORIA, F. de, CHAVES, T. de, Summa sacramentorum ecclesiae, Valladolid, Sebastián Martínez, 1561.

56 Con cinco ediciones publicadas en el período 1560-1563.

57 "Frater Thomas Chaues, in Sacra Theologia Praesentatus, familiae praedicatoriae minimus Candido lectori salutem", en: VITORIA, F. de, CHAVES, T. de, Summa sacramentorum ecclesiae, Salamanca, Andrea de Portonariis, 1565 .

${ }^{58}$ Hemos trabajado con la edición salmantina (Portonaris) de 1566, prácticamente idéntica a la de 1565 . "Commentariolus quo in compendium redactae errant observations inclyti praeceptoris mei fratris Francisci Victoriae, re, \& fama, super aethera noti in Quartum librum Sententiarum, quem ego attenta cura \& magna auiditate ex ore dicentis \& praelegentis, exceperam, mihi ipsi, ut thesaurum eximium seruaturus", Ibid.

59 "Nunc autem veluti repositam ad tempus tabulam reuisens, \& videns aliqua etiam quae secundam eamque propriam lineam desiderarent, libenti animo hoc quicquid est laboris assumpsi, ut opusculum ipsum, in lucem ipse publicam emitterem, castigatum, tersum, splendidumque, atque adeo locupletatum multis partibus. Recisa itaque sunt a nobis nonnulla superflua, additae sunt plures quaestiones dignissimae, quae praetermissae fuerant. Cuncta etiam adamusim Concilii Tridentini, sunt exacta, adhibitis in propriis locis decretis ipsius atque diffini-
} 
Trento, que Chaves cita antes de que concluya el Concilio ${ }^{60}$-, aunque, por razones estratégicas, prefiriera ocultarlo o minimizarlo hasta 1565. Oscilando ahora al extremo contrario, el dominico pide a los lectores de la obra en su nueva carta prefatoria que consideren inexistentes las ediciones anteriores ${ }^{61}$. Su petición resulta comprensible si pensamos en que, en muchos aspectos -por ejemplo, en lo tocante al matrimonio clandestino-, las opiniones de Vitoria eran totalmente opuestas a las aprobadas por el Concilio de Trento ${ }^{62}$ y debieron ser modificadas por Chaves después de 1563. Ello hace que, como indicaba Delgado de $\operatorname{Hoyos}^{63}$, cualquier estudio sobre la Summa sacramentorum que pretenda dar cuenta de la teología sacramental de Vitoria deba tener en cuenta sólo las ediciones anteriores a $1565^{64}$.

La epístola elaborada por Chaves para la edición de la Summa sacramentorum de 1565 constituye una descripción paradigmática del papel desempeñado por los epitomizadores en géneros literarios pragmáticos como las sumas, catecismos y manuales para párrocos, confesores, estudiantes y practicantes ${ }^{65}$. Deja claro

tionibus, quibus $\&$ doctrina ipsa fit augustior, $\&$ legentis animus optatam tranquillitatem inuenit, anxietate $\&$ mutatione sic prorsus exempta”, Ibid.

${ }^{60}$ Como mostraron Lanza y Toste reproduciendo un párrafo extraído de la primera cuestión sobre el bautismo, LANZA, L., TOSTE, M., "The Sentences in Sixteenth-Century Iberian Scholasticism”, op. cit., p. 445. Contiene una referencia a la Sesión VII del Concilio Tridentino no incluida en ninguno de los materiales manuscritos relacionados con la obra, lo que refuerza la hipótesis de que se trata de copias de un proyecto de publicación anterior.

61 "Et ea ipsis addita, adiunctaque; noua diligentia factum sit, ut libellus ille prior, iam merito sordere tibi debeat, hic autem quem in praesentia damus, omnino sit amplectendus, ut pote qui tot rationibus illi antecedat, tot commoditatibus eum exuperet, ut iam prae isto, ille nullus censeri queat", "Frater Thomas Chaues, in Sacra Theologia Praesentatus, familiae praedicatoriae minimus Candido lectori salutem”, en: VITORIA, F. de, CHAVES, T. de, Summa sacramentorum ecclesiae, Salamanca, Andrea de Portonariis, 1566.

${ }^{62}$ No me detendré en este tema en esta ocasión, al que me he referido en una publicación reciente, EGÍO GARCÍA, J. L., "Producing Normative Knowledge Between Salamanca and Michoacán: Alonso de la Vera Cruz and the Rocky Road of Books and Marriage”, en: DUVE, T., EGÍO GARCÍA, J. L., BIRR, C. (eds.), The School of Salamanca: A Case of Global Knowledge Production, Leiden, Brill (en prensa).

${ }^{63}$ DELGADO DE HOYOS, F., "Apuntes para la historia de la Escuela de Salamanca”, Anthologica annua 32 (1985), pp. 387-412, cit. p. 390.

${ }^{64}$ Éste es el principal problema que presentan los detallados estudios de Dioniso Borobio sobre los sacramentos "según Francisco de Vitoria". De forma un tanto incomprensible Borobio usa como material para reconstruir su pensamiento y doctrina la tercera versión del texto, muy alterada por Chaves y publicada originalmente en Salamanca en 1567 (Andrea de Portonaris), BOROBIO, D., Sacramentos en general. Bautismo y Confirmación en la Escuela de Salamanca. Fco. Vitoria, Melchor Cano, Domingo de Soto, Salamanca, Universidad Pontificia de Salamanca, 2006, pp. 19-20. Idéntico problema metodológico, que invalida buena parte del esfuerzo realizado por Borobio, en las dos monografías publicadas posteriormente, BOROBIO, D., Sacramentos en general: bautismo y confirmación en la Escuela de Salamanca: Fco. Vitoria, Melchor Cano, Domingo Soto, Salamanca, Universidad Pontificia de Salamanca, 2007; BOROBIO, D., Unción de enfermos, orden y matrimonio en Francisco de Vitoria y Domingo de Soto, Salamanca, Universidad Pontificia de Salamanca, 2008. https://doi. org/10.36576/summa.29736

${ }^{65}$ Géneros fundamentales para entender la inmensa labor de producción, localización y traducción cultural de conocimientos normativos que acompañó a la expansión ibérica en América. Once perspectivas recientes sobre 
que su papel no se limitaba a las tareas de los amanuenses o taquígrafos contemporáneos: aunque poco recordados y apreciados por la tradición historiográfica, personajes 'menores' como Chaves no sólo copiaban o registraban las lecciones de los 'grandes' maestros, sino que hacían un gran esfuerzo intelectual para condensar adecuadamente la 'sustancia' de los cursos, rellenar sus lagunas con contenidos extraídos de otros manuscritos y libros y distribuir sus contenidos en un orden de exposición fiel a las convenciones de este determinado género literario, pedagógicamente más adecuado. Los libros que trataban de temas jurídicos y normatividad religiosa resultaban particularmente difíciles de redactar y requerían una actualización continua, no pudiendo ignorarse acontecimientos trascendentales como la celebración de un Concilio o la aprobación de nuevas ordenanzas y cuerpos legales. La elaboración de índices y tablas con el fin de facilitar la consulta y el estudio de dichos contenidos figura también entre las tareas del epitomizador, responsable, por así decirlo, de que el conocimiento normativo y las resoluciones de casos y dudas llevadas a cabo por los 'grandes' maestros pudieran quedar al alcance de un público general y se difundieran por caminos más amplios que los que comunicaban los espacios académicos de la época, restringidos a una élite selecta.

La Summa sacramentorum constituye un material excepcional a partir del cual analizar las técnicas de epitomización utilizadas durante la Primera Modernidad. Efectivamente, resulta posible estudiar al detalle los procedimientos de condensación y reformulación a los que Chaves se refería en su "Epístola" de 1565 si se compara el contenido de la Summa impresa con los folios que tratan de las mismas materias en el manuscrito de la Biblioteca de Ajuda.

En una aproximación preliminar a estos materiales, Lidia Lanza y Marco Toste consideraron que en algunas cuestiones "the citations and the lines of reasoning are the same", aunque "the reasoning is much more developed in the Lisbon manuscript", siendo más complejo tanto en su estructura como en el número de autoridades y argumentos discutidos. Así, mientras que la Summa impresa suele referirse tan sólo a las posiciones de Tomás de Aquino, en el manuscrito lisboeta se intercalan también con frecuencia referencias a los comentarios a las Sentencias realizados por Buenaventura, Escoto, Pierre La Palud o John Mair, fuentes raramente mencionadas en la Summa Sacramentorum ${ }^{66}$.

el impacto de este tipo de literatura, hasta la fecha infravalorada en los estudios filosóficos e histórico-jurídicos, en la Iberoamérica colonial en el volumen DUVE, T., DANWERTH, O., Knowledge of the Pragmatici. Legal and Moral Theological Literature and the Formation of Early Modern Ibero-America, Brill, Leiden, 2020, https://doi.org/10.1163/9789004425736

${ }^{66}$ LANZA, L., TOSTE, M., “The Sentences in Sixteenth-Century Iberian Scholasticism”, op. cit., p. 447-449. 
Esas diferencias generales apuntadas por Lanza y Toste pueden rastrearse al detalle comparando diferentes secciones del libro y del manuscrito. Por ejemplo, si nos fijamos en una de las preguntas más breves analizadas en ambos materiales, una cuestión acerca de si las personas con discapacidad psicosocial ("furiosi et amentes" ${ }^{67}$ ) debían o no ser bautizadas (Ver Apéndice), podemos ver que la casuística y los argumentos son casi los mismos. En ambos textos ${ }^{68}$, el caso de los que ya nacieron con una discapacidad psicosocial (primer caso, a considerar siempre como "baptizandi"), se distingue de los diferentes casos de discapacidad incidental o sobrevenida. Dentro de éstos se distingue a su vez entre quienes mostraron su deseo de ser bautizados antes de enfermar (segundo caso, correspondiente a personas que deben ser también bautizadas), de aquellos que, antes de enfermar, nunca mostraron su disposición a ser bautizados o expresaron una determinación en este sentido (tercer caso, resuelto como "non baptizandi"). El cuarto caso planteado por Vitoria es el de aquellas personas temporalmente alteradas e incapacitadas psicosocialmente. En este último caso, Vitoria recomienda esperar hasta que la persona recobre sus facultades mentales plenas antes de proceder a la administración del sacramento del bautismo.

¿Cuáles son las diferencias entre ambos textos? Un primer cambio importante es el orden de exposición. En las lecciones de Vitoria recogidas en el manuscrito lisboeta, a la distinción entre los cuatro casos generales le sigue un subcaso muy específico derivado del caso del infiel que nunca quiso convertirse antes de enfermar (tercer caso). Vitoria se pregunta si en este caso la voluntad del párroco bastaría para proceder al bautismo, supliendo la del propio interesado como si se tratara de un niño. A continuación, evalúa Vitoria otro subcaso, derivado esta vez del segundo caso general de discapacidad sobrevenida. A su vez, de este subcaso se deriva otro subcaso en un orden de exposición muy desordenado y que dificulta mucho que el lector del manuscrito pueda seguir el orden lógico de la argumentación general.

\footnotetext{
${ }^{67}$ Cuestiones como ésta muestran el gran valor de los comentarios de Vitoria a la Summa, estrechamente interrelacionados con el resto de su producción intelectual. El tema de la amencia es recurrente en sus escritos. Como es sabido, uno de los interrogantes más importantes que se plantea Vitoria en su Relectio De Indis -y el único que, de hecho, deja sin resolver- es el hecho de si todos o algunos de los pueblos amerindios podían ser considerados "amentes" y de si esta hipotética amencia los hacía incapaces de ejercer dominio civil o político. "Alius titulus posset non quidem asseri, sed reuocari in disputationem, \& uideri aliquibus legitimus. De quo ego nihil affirmare audeo, sed nec omnino condemnare: \& est talis, Barbari enim isti, licet ut suprà dictum est, non omnino sint amentes, tamen etiam parum distant ab amentibus: ita uidetur, quod non sint idonei ad constituendam uel administrandam legitimam rem publicam etiam inter terminos humanos, \& ciuiles", VITORIA, F. de, Relectiones Theologicae, Lyon, Jacques Boyer, 1557, Tomus I, p. 371.

68 "An furiosi et amentes sunt baptizandi", VITORIA, F. de, Doctissimi Magistri .f. francisci de victoria ordinis praedicatorum sacrae theologiae in salmanticensi Academia quondam primarii professoris dictata in quartum librum sententiarum. Anno m. 5.5.8., [s.f.], Biblioteca de Ajuda (Lisboa), Ms. 44-XII-20, ff. 463-696; VITORIA, F. de, CHAVES, T. de, Summa sacramentorum ecclesiae, Valladolid, Sebastián Martínez, 1561, ff. $18 \mathrm{v}-19 \mathrm{r}$.
} 
Para facilitar la lectura y comprensión de la exposición, en la Summa sacramentorum el epitomizador Tomás de Chaves simplifica y abrevia la exposición, ordenando los argumentos de una manera más coherente y clara. En pro de la claridad, el subcaso derivado de un subcaso relacionado con el tercer tipo general de discapacidad psicosocial es totalmente eliminado. A su vez, las preguntas secundarias relacionadas con el segundo caso son planteadas y respondidas justo después de su formulación general.

Una segunda diferencia notable es que en la Summa sacramentorum se omiten las circunstancias contextuales relacionadas con algunas de las preguntas y casos planteados por Vitoria. Es evidente que los casos mencionados de adultos bautizables en estado de locura incidental sólo podían darse en tierras en proceso de conversión. En pro de la brevedad y con la intención de elaborar un manual pragmático aplicable en una gran variedad de contextos disímiles, el epítome de Chaves omite cualquier referencia contextual y tiende a formular éste y otros casos de la forma más abstracta posible. De acuerdo a la impresión que ofrece el manuscrito lisboeta, Vitoria abordaba en cambio las cuestiones recogidas en las Sentencias de Lombardo y otras obras clave de la traición teológico-moral y sacramental relacionándolas con circunstancias y situaciones muy concretas que se planteaban en las provincias atlánticas recientemente descubiertas. Dentro de este enfoque más contextual se formulan algunas preguntas extremadamente específicas, derivadas de los casos generales, que Chaves omitirá más tarde en su Summa: si la voluntad del párroco o misionero es suficiente para bautizar a un infiel afectado por una enajenación sobrevenida que nunca mostró disposición a convertirse antes de enfermar; si un infiel que, casado con su hermana -en estado, por tanto, de pecado mortal público-, mostró su deseo de ser bautizado, debería ser bautizado tras haber quedado en estado de amentia $^{69}$; si el bautismo administrado a tales pecadores les confiere gracia,...

El material manuscrito deja claro, por tanto, que Vitoria no se limitaba en sus clases a explicar, resumir o comentar las ideas de los grandes maestros de la antigüedad. Con grandes dosis de brillantez y originalidad, Vitoria actualizaba continuamente las doctrinas recibidas, se planteaba casos inéditos y producía los conocimientos normativos novedosos que su propia época exigía de él y de aquellos jóvenes teólogos a los que estaba formando ${ }^{70}$. El manuscrito de Lisboa nos confirma

\footnotetext{
${ }_{69}$ Este tipo de dilemas ultraoceánicos son tratados en la Summa sacramentorum de la forma más esquemática y abstracta posible. El caso del infiel casado con su hermana en una provincia lejana en estado de conversión pasa a ser, simplemente, el de cualquier persona en "peccato mortali", VITORIA, F. de, CHAVES, T. de, Summa sacramentorum ecclesiae (1561), f. 18v.

${ }^{70}$ Una perspectiva reciente sobre la Escuela de Salamanca como una comunidad discursiva orientada específicamente a la producción de conocimiento normativo en DUVE, T., "The School of Salamanca. A Case of Global
} 
también que, más allá del tratamiento monográfico que Vitoria dio a los llamados asuntos de Indias en sus relecciones De Indis, los descubrimientos ultraoceánicos y los desafíos políticos y religiosos planteados por los mismos constituyen un tema recurrente en su amplia producción intelectual.

La tercera diferencia sustancial entre manuscrito y obra impresa se deriva del hecho de que en esta última no sólo se simplifica el orden de exposición, sino que también se abrevia notablemente el contenido. Se suprimen, como decíamos, diversos subcasos y la mayoría de referencias a diversas autoridades. En este fragmento concreto, en la transición del manuscrito al impreso salen del texto todas las autoridades que Vitoria había tomado en consideración para determinar si el bautismo podía o no conferir la gracia a una persona en estado de pecado mortal, referencias detalladas a los escritos al respecto de Gabriel Biel y Tomás de Aquino. Este cambio implica, a su vez, que, a diferencia del tono habitual de las lecciones salmantinas, en las que Vitoria solía hacer hablar en su nombre a los maestros y autoridades de la tradición, en la Summa sacramentorum encontremos frecuentemente a un reforzado "ego" como sujeto enunciador. Las exigencias de brevedad propias del manual llevan también a que, en otros casos, los autores y libros mencionados sean reemplazados por un general e impersonal "doctores dicunt".

\section{Conclusión. El papel esencial de los discípulos mediocres. Tomás de Chaves y la emergencia de la Escuela de Salamanca.}

PeSE A SU BREVEDAD, las referencias ofrecidas resultan suficientes para tener una idea aproximada del tipo de procesos de epitomización puestos en práctica por Tomás de Chaves. Aunque este tipo de cometidos y figuras 'menores' han sido tradicionalmente despreciadas por una historiografía sobre la Escuela de Salamanca anclada en el paradigma romántico del 'genio creador' y que ha tendido a reducir la Escuela al diálogo entre una decena de grandes maestros, tanto Chaves como su labor resultaron esenciales para que el pensamiento de Vitoria pudiera emprender un largo viaje desde las aulas de Salamanca al mundo de los libros y de los libros al mundo entero, colonizando no sólo nuevos continentes sino también una multitud de espacios (parroquias, confesionarios, concilios eclesiásticos provinciales, juntas de teólogos y juristas,...), de características diferentes a la esfera académica en la que se había gestado.

Knowledge Production", en: DUVE, T., EGÍO GARCÍA, J. L., BIRR, C. (eds.), The School of Salamanca: A Case of Global Knowledge Production, Leiden, Brill (en prensa). 
A pesar del olvido en que los estudiosos han mantenido estos materiales, la Summa sacramentorum impresa, el primer proyecto abortado y los materiales manuscritos derivados del mismo constituyen hitos importantísimos en el progresivo surgimiento de la figura de Vitoria como iniciador de una Escuela de pensamiento. Como reza el título del MSS/49 de la BPE de Cáceres, antes incluso de que muera el maestro, antiguos alumnos como Chaves comienzan a preservar y difundir su legado presentándose como sus "fieles discípulos".

La perspectiva institucionalista, que considera miembros de la Escuela sólo a aquellos maestros que llegaron a ocupar cátedras en la Facultad de Teología de la Universidad de Salamanca ${ }^{71}$, elitista y aristocrática, falsea profundamente la realidad histórica. Aunque perspectivas semejantes fueron empleadas recurrentemente desde mediados del siglo XIX para construir el canon de una historia de la filosofía occidental entendida como el debate entre un puñado de grandes genios, la renovación historiográfica emprendida desde, al menos, la década de los setenta, ha transformado profundamente esta perspectiva anacrónica. En este sentido, resulta imposible, hoy en día, comprender la emergencia y desarrollo de cualquier escuela de pensamiento sin atender a una larga serie de personajes oscuros y quizá mediocres intelectualmente, pero que con su acción como copistas, transmisores, epitomizadores y divulgadores de las doctrinas de los grandes maestros, hicieron posible, precisamente, que la renovación de los estudios teológicos propuesta por Vitoria y la comunidad intelectual en la que se movía llegaran a vertebrarse como una auténtica escuela de pensamiento. Desde una perspectiva histórica y social, personajes mediocres como Tomás de Chaves, Alonso Muñoz o el igualmente oscuro bachiller Francisco Trigo -a quien debemos buena parte de las anotaciones manuscritas empleadas para reconstruir el contenido de las lecciones de Vitoria sobre la Summa theologiae- resultan tan importantes como Vitoria, Soto y Cano. En efecto, mientras que son muchos los pensadores que, a lo largo de la historia, han llevado a cabo obras e iniciativas geniales de forma aislada, sólo donde contamos con Chaves, Muñoces y Trigos se dan las condiciones para que fermente una escuela de pensamiento y podemos hablar, propiamente, de ella.

\footnotetext{
${ }^{71}$ La Escuela sería, desde esta perspectiva, una escuela de teólogos, "limitada a aquellos docentes de la Universidad, dominicos y no dominicos, que en la explicación de santo Tomás en sus clases y escritos se atuvieron a las pautas que desde el convento de San Esteban se fueron marcando", BARRIENTOS GARCÍA, J., Repertorio de moral económica (1536-1670). La Escuela de Salamanca y su proyección, Pamplona, EUNSA, 2011, p. 84.
} 


\section{APÉNDICE}

"Amentes \& furiosi, an sint baptizandi?", VITORIA, F. de, CHAVES, T. de, Summa sacramentorum ecclesiae, Valladolid, Sebastián Martínez, 1561, ff. 18v-19r.

QVÆritur, vtrum amentes, \& furiosi sint baptizandi? Respondeo, quod si aliquis sit perpetuo amens, quia sic natus est, \& nunquàm habuit vsum rationis, talis est baptizandus, quia idem est iudicium ac de puero. Secundò dico quod si amens habuit aliquando usum rationis, \& tunc cum erat sui compos voluit baptizari, licet posteà inciderit in amentiam est baptizandus sine dubio. Verum est quòd si quandò habuit vsum rationis, \& voluit baptizari, constet eum esse in aliquo peccato mortali à quo nolebat abstinere, male faceret qui eum baptizaret. Si autem talis de facto baptizetur, vtrum consequatur gratiam? Doctores concorditer dicunt, quòd nibil sibi proficeret baptismus. Nec ego oppositum auderem determinatè dicere, probabile tamen existimo, cùm baptismus sit in remedium peccatorum, quòd habet efficaciam erga attritum qui est in mortali. Et potest etiam baptizari cum sit in originali talis furiosus, quòd si baptizetur in casu dicto saluabitur, ne ponamus aliquem in via extra statum salutis. Hoc credo multum probabile.

Tertiò dico quod si talis cum habuit vsum rationis noluit baptizari posteá lapsus in amentiam non potest baptizari, quia voluntas praterita reputatur prasens, \& si baptizetur nibil ei valet baptismus vt videtur. Quartò dico quod si sit talitèr amens de quo creditur quod redibit in pristinam sanitatem, etiam si ante amentiam voluerit baptizari, non est baptizandus sed propter reuerentiam sacramenti expectanda est eius conualescentia: dum modo non sit periculum de morte eius.

"An furiosi et amentes sunt baptizandi", VITORIA, F. de, Doctissimi Magistri .f. francisci de victoria ordinis praedicatorum sacrae theologiae in salmanticensi Academia quondam primarii professoris dictata in quartum librum sententiarum. Anno $\mathrm{m}$. 5.5.8., [s.f.] ${ }^{72}$.

Quaeritur an furiosi et amentes sunt baptizandi respondetur ab omnibus per Propositiones. Prima quod si tales sint amentes vel furiosi á nativitate baptizandi sunt sicut alij pueri. 2a. sinon fuerint amentes á nativitate, videndum est an tempore usus rationis habuerint voluntatem ad baptizandum \& tunc sunt baptizandi. Tertia quod si tempore usu rationis non ostenderunt verbis aut signis se velle baptizari non sunt baptizandi. Quarta quod si est cui quod aliquando per intervala resipiscunt et antea voluerint baptizari spectandum est usque ad illud tempus, ut maiori cum honore suscipiant baptismum. Sed haec Propositio est debere esse, sed circa tertium dubitatur, nam volo quod talis amens sit ex aliqua Provincia quae tota modo ad deum convertatur an

\footnotetext{
72 Agradezco a Natalie Cobo la ayuda prestada en la transcripción de algunas palabras del siguiente pasaje.
} 
talis tunc esset baptizandus cum Pater vellit illum baptizari licet iste ante volluisset in usu rationis mihi videtur quod nullo modo est baptizandus cum voluntas eius Prior interpretative sit illa quod est nunc, signis vellet oppositum dicere aseveraret tunc quod voluntas Patris est voluntas eius sicut in Pueris, sed ego id non credo. Praeterea quaeritur an si quis habuisset sororem pro uxore et vellet baptizari nollens eam dimittere et postea cadat in amentiam cum tali voluntate et Proposito an sit baptizandus, videtur quod non quia ille est in peccato mortali publico, ergo esset sacrilegium illi sacramentum ministrari. Respondeo, quod si talis non asequeretur gratiam per baptismum sacrilegium esset baptizare illum, sed quaeritur an per baptismum remitteretur illi peccatum mortale Gabriel hac distinctione q. 2. dicit quod talis qui erat ante in peccato mortali modo non assequeretur gratiam et sic infert quod talis est extra statum salutis, licet ego non audeam dicere oppositum habet tamen maximam probabilitatem \& est de mente Sancti Thomae. 3. Parte q. 68. ubi quaerit an Peccatores sint baptizandi et dicit quod exens in peccato mortali cum atritione si baptizetur consequetur gratiam, quidquid sit iam diximus quod in talibus adultis? qui habent peccata mortalia requiritur dolor de Peccatis ideo licet iste sit veré baptizatos gratiam tamen non suscipit. 


\section{Referencias Bibliográficas}

\section{Fuentes manuscritas}

VITORIA, F. de, CHAVES, T. de, Summa sacramentorum ecclesiae, ex doctrina eggregij et doctissimi viri fratris Francisci a victoria, in sacra theologia Magistri, cathedram prima in Salmanticensi florentissima academia profitentis, congesta per fratrem Thomam de chaves eius fidelem discipulum, \& ex ipso compilatoris exemplari primo transcripta, Quam et ipse idem magister ad discipuli preces perlegit Salmanticae Anno 1541. Mense Octobri. MSS/49, Cáceres. Biblioteca Pública del Estado "A. Rodríguez-Moñino/M. Brey".

VITORIA, F. de, [CHAVES, Tomás de], Scholia magistri Francisci a Vitoria in compendium redacta super 4 um librum Sententiarum, Madrid, Biblioteca Nacional de Espana (BNE), MSS/13923, ff. 1r-215v.

\section{Fuentes impresas}

BARBOSA MACHADO, D., Bibliotheca lusitana historica, critica e cronologica, Vol. IV, Lisboa, Ignacio Rodrigues, 1752.

CARRANZA, B. de, Comentarios sobre el catecismo cristiano, Amberes, Martín Nucio, 1558.

Marieta, J. de, Historia Eclesiastica de todos los santos, de España. Segunda parte, Cuenca, Pedro del Valle, 1596.

MELÉNDEZ, J., Tesoros Verdaderos De Las Yndias en la Historia de la gran provincia de San Juan Bautista del Perú de el Orden de Predicadores, Roma, Nicolás Ángel Tinassio, 1682.

QUÉTIF, Jacques, ECHARD, Jacques, Scriptores ordinis praedicatorum, París, Ballard / Simart, 1721.

SAVONAROLA, G., Homiliae, Salamanca, Juan de Canova, 1556.

VELASCO Y HERRERA, S. S. de, Compendio de la nobilissima fundacion y privilegios del Colegio Mayor de Señor S. Clemente de los españoles de Bolonia, [Sevilla], Juan Francisco de Blas, 1695.

VITORIA, F. de, Relectiones Theologicae, Lyon, Jacques Boyer, 1557. 
VITORIA, F. de, CHAVES, T. de, Summa sacramentorum, Valladolid, Sebastián Martínez, 1560.

VITORIA, F. de, CHAVES, T. de, Summa sacramentorum ecclesiae, Salamanca, Andrea de Portonariis, 1566.

VITORIA, F. de, CHAVES, T. de, Summa Sacramentorum, Salamanca, Domingo de Portonaris, 1570.

VITORIA, F. de, CHAVES, T. de, Confessionario util y provechoso, Santiago, [Luis de Paz], 1562.

XIMÉNEZ ARIAS, D., Lexicon ecclesiasticum latinohispanicum ex sacris Bliblijs Conciliis, Pontificum ac theologorum decretis, divorum vitis, varijs Dictionarijs, aliisque probatissimis scriptoribus concinnatum, Barcelona, Sebastián de Cormellas, 1613 (ed. orig. Salamanca, Andrea de Portonaris, 1566).

\section{Bibliografía secundaria}

ALONSO GETINO, L., El maestro Fr. Francisco de Vitoria: su vida, su doctrina e influencia, Madrid, Asociación Francisco de Vitoria, 1930.

BARRIENTOS GARCÍA, J., Repertorio de moral económica (1536-1670). La Escuela de Salamanca y su proyección, Pamplona, EUNSA, 2011.

BELTRÁN DE HEREDIA, V., Los manuscritos del maestro fray Francisco de Vitoria, Biblioteca de Tomistas Españoles, Madrid / Valencia, 1928.

BELTRÁN DE HEREDIA, V., Bulario de la Universidad de Salamanca (12191549), Vol. I, Salamanca, Universidad de Salamanca, 1966.

BELTRÁN DE HEREDIA, V., "Las corrientes de espiritualidad entre los dominicos de Castilla”, en: Beltrán de Heredia, V., Miscelánea Beltrán de Heredia, Salamanca, OPE, 1972, pp. 519-671.

BOROBIO, D., Sacramentos en general. Bautismo y Confirmación en la Escuela de Salamanca. Fco. Vitoria, Melchor Cano, Domingo de Soto, Salamanca, Universidad Pontificia de Salamanca, 2006.

BOROBIO, D., Sacramentos en general: bautismo y confirmación en la Escuela de Salamanca: Fco. Vitoria, Melchor Cano, Domingo Soto, Salamanca, Universidad Pontificia de Salamanca, 2007.

BOROBIO, D., Unción de enfermos, orden y matrimonio en Francisco de Vitoria y Domingo de Soto, Salamanca, Universidad Pontificia de Salamanca, 2008. https://doi.org/10.36576/summa.29736 
CABAllerO, F., Vida del Illmo. Sr. D. Fray Melchor Cano, del orden de Santo Domingo, obispo de Canarias, etc., Madrid, Imprenta del Colegio Nacional de Sordo-Mudos y de Ciegos, 1871.

CASTILLA URBANO, F., El pensamiento de Francisco de Vitoria. Filosofía politica e indio americano, Barcelona / México, Anthropos / UAM Iztapalapa, 1992.

COUJOU, J. P., ZORROZA, M. I., Bibliografía vitoriana, Pamplona, EUNSA, 2014.

CUERVO, J., Historiadores del convento de San Esteban de Salamanca, Salamanca, Imprenta Católica Salmanticense, 1914.

DELGADO DE HOYOS, F., "Apuntes para la historia de la Escuela de Salamanca", Anthologica annua 32 (1985), pp. 387-412.

DÍAZ DÍAZ, G., Hombres y documentos de la filosofía española, Vol. 2, Madrid, CSIC, 1983.

DUVE, T., DANWERTH, O., Knowledge of the Pragmatici. Legal and Moral Theological Literature and the Formation of Early Modern Ibero-America, Brill, Leiden, 2020. https://doi.org/10.1163/9789004425736

DUVE, T., "The School of Salamanca. A Case of Global Knowledge Production", en: DUVE, T., EGÍO GARCÍA, J. L., BIRR, C. (eds.), The School of Salamanca: A Case of Global Knowledge Production, Leiden, Brill (en prensa).

EGÍO GARCÍA, J. L., "Producing Normative Knowledge Between Salamanca and Michoacán: Alonso de la Vera Cruz and the Rocky Road of Books and Marriage”, en: DUVE, T., EGÍO GARCÍA, J. L., BIRR, C. (eds.), The School of Salamanca: A Case of Global Knowledge Production, Leiden, Brill (en prensa).

GRAWERT, R., "Francisco de Vitoria: Naturrecht - Herrschaftsordnung Völkerrecht”, Der Staat 39:1 (2000), pp. 110-125, p. 114.

GONZÁLEZ, R., Francisco de Vitoria. Estudio bibliográfico, Buenos Aires, Institución Cultural Española, Buenos Aires, 1946, p. 33.

HOYOS, M. de los, Registro historial de la provincia de España, Segunda parte, Tomo I, Conventos de la Primera Orden, Madrid, 1966.

ISERLOH, E., GLAZIK, J., JEDIN, H., History of the Church. Vol. V. Reformation and Counter Reformation, Londres, Burns \& Oates, 1980.

JONES MATHERS, C., "Students from Burgos at the Spanish College at Bologna (1500-1560)", The Sixteenth Century Journal 18:4 (Winter, 1987), pp. 545-556. https://doi.org/10.2307/2540869 
LANZA, L., TOSTE, M., "The Sentences in Sixteenth-Century Iberian Scholasticism", en: ROSEMANN, P. W., Mediaeval Commentaries on the Sentences of Peter Lombard, Vol. 3, Leiden, Brill, 2015, pp. 416-503. https://doi. org/10.1163/9789004283046 010

LEONARD, I., Books of the Brave, California, University of California Press, 1992.

MARCOS DE DIOS, Á., "Portugueses en la Universidad de Salamanca en la Edad Moderna”, en: RODRÍGUEZ SAN PEDRO-BEZARES, L. E. (ed.), Historia de la Universidad de Salamanca, III. 2: Saberes y confluencias, Salamanca, Universidad de Salamanca, 2006, pp. 1101-1128.

PASTORE, S., Una herejía española. Conversos, alumbrados e Inquisición (14491559), Madrid, Marcial Pons, 2010.

RAMÍREZ GONZÁLEZ, C. I., Grupos de poder clerical en las universidades hispánicas. Volumen 2, Los regulares en Salamanca y México durante el siglo XVI, México, UNAM, 2002.

RAMÍREZ GONZÁLEZ, C. I., La Universidad de Salamanca en el siglo XVI. Corporación académica y poderes eclesiásticos, Salamanca, Universidad de Salamanca, 2002.

SÁINZ DE BARANDA, P., Noticia sobre la vida de D. Fr. Bartolomé Carranza de Miranda, Arzobispo de Toledo, Madrid, Viuda de Calero, 1845.

TELLECHEA IDÍGORAS, J. I. (ed.), Fray Bartolomé de Carranza. Documentos históricos. III Testificaciones de abonos, indirectas y tachas, Madrid, Real Academia de la Historia, 1966.

TELLECHEA IDÍGORAS, J. I., Bartolomé Carranza. Estudios Completos II: El trauma nacional religioso de 1558-1559: estudio y epistolario, A Coruña, Mendaur, 2019.

URDÁNOZ, T., "Introducción”, en: VITORIA, F. de, URDÁNOZ, T. (ed.), Obras de Francisco de Vitoria: relecciones teológicas, Madrid, BAC, 1960.

WILKINSON, A., Iberian Books: Books Published in Spanish or Portuguese or on the Iberian Peninsula before 1601, Brill, Leiden / Boston, 2010.

YHMOFF CABRERA, Jesús, Catálogo de los impresos europeos del siglo XVI que custodian la Biblioteca Nacional, Tomo I, México, UNAM, 1996.

DOI: https://doi.org/10.15366/bp2021.26.004

Bajo Palabra. II Época. No26. Pgs: 75-106 